\title{
A prática de ensinar: dialogando com as professoras de enfermagem
}

\author{
The practice of teaching: a dialogue with professors of nursing \\ La práctica de enseñar: dialogando con las maestras de enfermería
}

\section{Maria Zélia de Araújo Madeira', Maria da Glória Soares Barbosa Lima' \\ 'Universidade Federal do Piauí. Teresina, PI}

Submissão: 19/03/2008

Aprovação: 3 1/07/2008

\section{RESUMO}

Este artigo tem como objetivos discutir e explicitar a prática pedagógica cotidiana do docente de enfermagem da UFPI. Trata-se de um estudo de natureza Qualitativa, com ênfase metodológica na História Oral, tendo como sujeitos-interlocutores professores do curso de enfermagem da referida IES e como instrumentos de produção de dados: entrevistas semi-estruturadas. A análise de dados efetivouse a partir da análise de conteúdo. As docentes de enfermagem consideraram em suas narrativas orais o propósito de romper com a forma vertical de ensinar ao estimular no aluno o poder da criatividade e da compreensão da realidade em permanente transformação. Descritores: Ensino; Educação em enfermagem; Docente de enfermagem.

\section{ABSTRACT}

The aim of this study is discuss the daily practice of the nursing professors at the Federal University of Piauí. The study was accomplished in a Qualitative approach with methodological emphasis on Oral History with the primary subjects being professors of nursing at the Federal University of Piauí. The instrumento for data collection was semi-structured interviews and data analysis was realized through content analysis. The nursing educators are considering the possibility of breaking with the vertical teaching method in order to stimulate the power of creativity and understanding within the student body which finds itself in a permanent state of transformation.

Descriptores: Teaching; Education, nursing; Nursing Educators.

\section{RESUMEN}

Este artículo tiene como objetivos discutir y explicitar la práctica cotidiana del docente de enfermería de la UFPI. Estudio de naturaleza cualitativa, con énfasis metodológico en la Historia Oral, teniendo como instrumentos la colecta de datos, entrevistas semi-estructuradas usando los profesores de enfermeria de IES como los sujetos, y el análisis de datos del análisis de contenido. Las docentes de enfermería consideraron que se puede romper con la verticalización de la enseñanza al estimular en el alumno el poder de la creatividad y de la comprensión de la realidad en permanente transformación.

Descriptores: Enseñanza; Educación en enfermería; Docente de enfermería. 


\section{INTRODUÇÃO}

A reflexão acerca do processo educativo nas suas dimensões social, histórica, filosófica e instrumental, possibilita compreender a educação e, mais particularmente, os processos de ensinar e de aprender na universidade, enQuanto instâncias diferenciadas em termos conceptuais, mas Que, em termos dimensionais, pela importância Que encerram, têm a mesma magnitude assim como em termos de relações, nos Quais o sujeito do ensino, neste caso o professor, estabelece conexões entre sua subjetividade e o ambiente, produzindo, assim, os saberes necessários ao desenvolvimento da prática pedagógica.

No intuito de compreender e melhor aprofundar as Questões relativas às orientações didático-pedagógicas na prática docente de enfermagem, principalmente as de caráter metodológico ${ }^{(1,2)}$, há dois grupos de teorias Que conduzem à compreensão de um processo de aprendizagem Que começa e termina nelas próprias.

No primeiro grupo, estão as teorias não-críticas as Quais encaram a educação como autônoma e buscam compreendê-la a partir dela mesma, a exemplo, da pedagogia tradicional, da pedagogia nova e da pedagogia tecnicista. O segundo grupo integra as teorias críticas, correspondentes às vertentes: pedagogia problematizadora, expressa através do "método do arco", caracterizada principalmente pela participação ativa e pelo diálogo constante entre alunos e professores.

Vale considerar também Que as várias correntes pedagógicas sobre a natureza do conhecimento determinam diferentes concepções acerca dos modos de ensinar na escola. E vários significados atribuídos ao ato de ensinar, destacando-se dois que parecem predominar no âmbito da prática pedagógica: o primeiro refere-se à concepção de ensino-aprendizagem como simples transmissão de conteúdo; e o segundo Que compreende a concepção de prática pedagógica como um trabalho de descoberta, de pesquisa. Essas concepções determinam diversificados modos de ensinar Que, por sua vez, determinam diferentes formas de relação pedagógica.

A prática pedagógica como evidenciada no estudo por nós desenvolvido, ocorre num contexto de relações entre profissão docente, profissionalidade e formação do professor, ou seja, em meio à necessidade de ampliar e de Qualificar a prática profissional na docência superior, Que, em geral, tem tramitado pelo exame de diferentes esquemas oue a regem, à luz de seus princípios e, ainda, pelo enfrentamento sistemático dos dilemas e das relações de poder Que nela manifestam ${ }^{(3)}$.

A compreensão é, pois, Que a formação do professor $^{(4)}$ deve fomentar os processos reflexivos sobre a educação e sobre realidade social, por meio de diferentes experiências, gerando uma atitude interativa e dialética Que conduza à necessidade de uma atualização permanente em função das mudanças Que possam ser produzidas.

Assim, o processo formativo de professores ${ }^{(5)}$ também indicia e anuncia a valorização da escola e de seus profissionais nos processos de democratização da sociedade brasileira, a razão por Que ressalta a significância da contribuição do saber escolar na formação da cidadania, na organização da escola, nos currículos, nos espaços e nos tempos de ensinar e aprender. Inclui, ainda, como pontos, significativos, o projeto político e pedagógico, os alunos, os professores e a própria profissão, visto Que todos contribuem para exercitar a reflexão acerca da docência, da valorização da profissão docente, dos saberes dos professores, do trabalho coletivo docente e da escola eneuanto espaço de formação contínua.

A compreensão Que avulta é Que o professor pode produzir conhecimento a partir da sua prática pedagógica, desde Que, na condução desse processo, na etapa Que compreende a investigação, reflita intencionalmente sobre ela, problematizando-a com o suporte da teoria, com os resultados obtidos, agindo, de fato, como efetivo pesquisador de sua prática.

Volvendo um olhar especial para a prática pedagógica ${ }^{(6)}$ no ensino universitário esta aponta para a perspectiva de um paradigma inovador na sociedade do conhecimento e da informação. Ou seja, incita o professor a sentir-se desafiado a buscar uma prática pedagógica Que contemple a produção do conhecimento, como alicerce de sua docência cotidiana. O paradigma emergente inclui, entre outros, uma visão sistêmica ou holística, Que busca a superação do conhecimento estático, propondo uma abordagem progressiva, Que promova o diálogo e a discussão coletiva, crítica e reflexiva entre alunos e professores, no ensejo de Que o ensino e a pesquisa visem, sobretudo, à produção do conhecimento, com autonomia e espírito crítico e investigativo.

O presente artigo, portanto, decorre da dissertação realizada no Mestrado em Educação. Trata-se, pois, de uma das categorias de análise do referido estudo, denominada "A construção da prática de ensinar: o Que dizem as professoras do curso de enfermagem" e de suas conseqüentes subcategorias: As professoras e o desenvolvimento da prática pedagógica; Dilemas na organização do trabalho docente; e Possibilidades de construção de uma prática reflexiva. Nesse sentido, de forma geral, objetiva discutir e explicitar a prática pedagógica cotidiana do docente de enfermagem da UFPI.

\section{METODOLOGIA}

O estudo caracteriza-se, pois, como de natureza Qualitativa, na modalidade descritivo-interpretativa, com ênfase metodológica na História Oral ${ }^{(7)}$, tendo empregado como instrumentais de produção de dados entrevistas semi-estruturadas junto 10 (dez) professoras do Departamento de Enfermagem da UFPI, Que para efeito de identificação receberam nomes fictícios. A análise de dados efetivouse a partir de uma base categorial, orientada pela técnica da análise de conteúdo ${ }^{(8)}$. Implica dizer Que, no seu todo a investigação tratou com 3 (três) categorias, das Quais como já evidenciado, recortamos a categoria 01 : A construção da prática de ensinar: o que dizem as professoras do curso de enfermagem e suas decorrentes subcategorias.

A narrativa de si por meio da História Oral nos faz adentrar a territórios existenciais, em significados construídos/desconstruídos sobre a docência, bem como no Que diz respeito às aprendizagens construídas. Desse modo, com base nas categorias apontadas pelo aporte de dados e a partir de sua conseeüente leitura compreensiva, iniciou-se de fato, a análise e discussão dos dados. Assim, fomos constatando a importância do trabalho com memórias reconstruídas através da História de Oral das professoras de enfermagem.

A etapa dedicada à coleta de dados começou no mês de setembro de 2005, com término no mês de abril de 2006. Foi solicitado o Termo de Consentimento junto aos sujeitos participantes do estudo, levando em consideração os aspectos éticos propostos 
pela Resolução 196/1996, do Conselho Nacional de Saúde, sobre pesQuisas envolvendo seres humanos ${ }^{(9)}$.

\section{RESULTADOS E DISCUSSÃO}

A construção/ (re) construção do sentido de prática pedagógica através do trabalho com a memória oral justifica-se, primordialmente, pela possibilidade de empreendermos reflexões sobre esses relatos, no sentido de permitir às professoras darem uma nova dimensão à sua prática profissional a partir dos referenciais Que a marcaram, bem como diante da percepção do desenvolvimento de sua profissionalidade docente.

As reflexões realizadas pelas professoras interlocutoras em relação à construção de suas práticas de ensinar mostraram Que, no desempenho das atividades de ensino no curso de enfermagem, há compromisso e envolvimento com esse trabalho, aliando a essa compreensão a visão de complexidade Que, no geral, marca o processo ensino-aprendizagem. Destacamos, inclusive, Que o processo reflexivo emergiu do exercício de análise dos dados integrantes das três subcategorias, a saber:

a) As professoras e o desenvolvimento da prática pedagógica

Nesta subcategoria, as professoras do curso de enfermagem relatam como desenvolvem a sua prática diária e Quais ferramentas educativas utilizam. As professoras ao se defrontarem com os problemas da sala de aula, Que, a rigor, são bastante complexos, lançam mão de um conhecimento profissional construído na vivência da prática pedagógica, tomando como ponto de partida a gestão do conteúdo e os conhecimentos prévios dos alunos de forma original e, muitas vezes, de forma criativa, elaborando sua própria maneira de atuação na sala de aula. Neste sentido, são elucidativas as falas das interlocutoras no Que concerne aos meandros dessa prática:

O planejamento em sala de aula é muito importante e eu sempre solicito sugestões deles (alunos) mais eles não dão sugestões (Edma).

Eu tento incentivar que ele se coloque porque na verdade o ensino é uma troca de aprendizagem entre aluno e professor, então não existe aquilo de o professor saber mais que o aluno, todos dois tem conhecimento (Isaura).

O professor ele precisa ter além do domínio (conteúdo) ele precisa ter uma postura cênica, criativa muito boa, a postura cênica do professor é imprescindível, porQue às vezes o professor domina, mas, ele não consegue passar para o aluno, porque ele não tem uma postura cênica, eu aprendi isso (Mariana).

Eu ministro outra disciplina, Bases técnicas, é uma disciplina dada muito na prática pedagógica tradicional, ou seja, da transmissão somente, do ensino tradicional, do aluno passivo e Que você fica falando tudo àQuilo que sabe e ele só recebendo, mas no fim você não vê mudança nele (Lais).

As narrativas analisadas revelam elementos necessários à prática pedagógica (saber, saber-fazer e saber-ser). Expressam que o professor, além de conduzir de forma competente a gestão pedagógica e disciplinar da sala de aula, para exercer o ofício de ensinar, necessita, entre outras coisas, conhecer os alunos e acreditar em suas potencialidades. A esse respeito ${ }^{(10)}$ reportam-se aos elementos Que compõem a base de conhecimentos para a docência, isto é, a um conhecimento Que dá conta, no âmbito da prática pedagógica, dos conteúdos das disciplinas curriculares, ou seja, refere-se ao conhecimento da matéria Que leciona.

Agregados a este tipo de conhecimento, estão: o conhecimento pedagógico geral (processo pedagógico, motivação, estilos de aprendizagem e etc.); o conhecimento curricular; o conhecimento dos fins e das metas da educação e dos contextos educacionais, e finalmente, o conhecimento dos alunos, de seus específicos estilos de aprendizagem ${ }^{(10)}$.

É importante também verificar Que nessa condução de reflexões em torno da prática pedagógica, a postura das professoras parece contribuir para Que os alunos repensem suas incertezas e as visões consolidadas, exercício que melhor se eualifica euando mediado pelo professor. Desse modo, ao refletirem acerca desta Questão, apontam a importância Que o diálogo ${ }^{(11)}$ representa um instrumento por excelência do professor para possibilitar a produção de conhecimentos em sala de aula. Entendemos, pois, ser importante valorizar sempre a realidade do aluno, seu universo e o conhecimento Que traz de seu grupo social, contribuindo com seu processo de sentir-se sujeito do mundo escolar mediante uma didática contextualizada/ressignificada.

O saber da escuta e do diálogo, revelado nas falas das professoras/parceiras, aponta para a necessidade de criar espaços para Que os alunos se expressem, motivando o professor para ouvir o Que é dito, acolhendo as falas, sem julgamento ou depreciação, imprimindo ao seu fazer docente uma dinâmica de ensino pautada em bases democráticas, na dialogicidade.

Nessa perspectiva, as professoras do curso de enfermagem, todas, com maior ou menor intensidade, evocam sua prática pedagógica, revelando, em maior proporção, a vivência da prática construída na interação com o alunado, compreensão corroborada pelos depoimentos das interlocutoras, a exemplo do Que refere: Edma " $[$...] eu sempre solicito sugestões deles [...]", ou como ilustra a fala de Isaura "Eu tento incentivar Que ele se coloque [...]".

Mariana menciona um elemento "novo" (coadjuvante) à tarefa do professor em aula, trata-se de "[...] uma postura cênica [...]", o Que não significa Que o espaço da sala de aula seja palco de uma peça teatral, mas Que o professor com sua maestria deve compreender os vários planos e as várias etapas a desenvolver numa situação de aula, isto é, de ensino e de aprendizagem. Assim é Que, Lais, ao falar da construção de sua prática pedagógica, expressa seu desconforto, e especialmente sua discordância com certos modelos de aula em Quais em Que o professor muito verbaliza (fala muito), o que ela denomina de "ensino tradicional", em Que não há interação efetiva com o aluno Que, neste caso, assume papel passivo, de modo não consegue, concretamente, contribuir para ocorrer à necessária mudança (aprendizagem).

Logo, se por um lado, a professora Lais revela o desenvolvimento de uma prática pedagógica tradicional, em conjunto com outros professores, por outro lado, reconhece as fragilidades que a permeiam, inclusive tece considerações críticas em relação ao desenvolvimento desta prática. Acerca de uma prática pedagógica 
pautada na racionalidade técnica ${ }^{(12)}$ recomenda/discute a necessidade de superação dessa prática acrítica, repetitiva, adotando, dentre outros requisitos, o desenvolvimento de uma ação docente crítico-reflexiva, configurando a prática pedagógica enQuanto uma prática social Que conjuga a relação teoria-prática, e necessita de intervenções positivas para viabilizá-la.

Ainda considerando acerca desta subcategoria, as professoras interlocutoras, ao refletirem sobre o desenvolvimento da prática pedagógica, afirmaram Que como procedimentos metodológicos, usualmente, costumam privilegiar aulas expositivas e de demonstrações, oportunizando momentos do aprender fazendo, bem como enfatizando a troca de saberes entre professor e alunos.

Portanto, reforçando este olhar analítico, destacamos os seguintes recortes narrativos, no Que se refere ao desenvolvimento da prática pedagógica, pois são elucidativos neste sentido, segundo as falas a seguir:

Eu faço dinâmica de grupo e aula expositiva. Primeiro nós discutimos aquela temática, cada um colocando seus pontos essenciais e depois dessas apresentações o aluno fecha a discussão, eu considero que dessa forma todos (professor e aluno) aprendam mais (Edma).

O diálogo precisa ser trabalhado e bem conduzido por parte do professor e do aluno, a comunicação na enfermagem é primordial (Isaura).

Acredito que a aprendizagem é uma troca contínua, não sou o poder absoluto dentro da sala de aula, gosto que o aluno discuta e Questione o meu ponto de vista (Mariana).

Quando eu dou aula em círculo eu explico porque a roda, a roda é uma técnica de troca de saberes, conhecimentos e explico como se dará a aula e eu estou achando que isso é melhor [...] Então por isso que eu digo Que teoria e prática são indissociáveis. E mesmo a enfermagem sendo de intervenção técnica, o aluno tem condições de construir (Lais).

O ensino na enfermagem e nas outras áreas é uma troca de saberes, de verdades, de acertos e de erros Que estão sempre sendo chamados a discutir com a participação do professor, dos alunos e do paciente, pois todo nosso conhecimento tem por finalidade o cuidar, cuidar das pessoas, eu tenho essa necessidade de ouvir, por exemplo, o que esse aluno pensa desse cuidar (Zaira).

Os depoimentos das professoras interlocutoras Edma "[...] cada um colocando seus pontos essenciais [...]" e Lais "[...] a roda é uma técnica de troca de saberes [...]" indicam Que o desenvolvimento da prática pedagógica, em face de sua complexidade, requer uma diversidade de estratégias de ensino como forma de apoiar e efetivar as ações de ensino do professor e de aprendizagem dos alunos. Neste âmbito, nossas interlocutoras demonstram perceber Que o processo de ensino não possui um rigor técnico, fazendo-se importante Que o docente organize de forma dinâmica o seu trabalho, considerando nesse processo o conhecimento prévio do aluno. Em suas reflexões sobre a prática pedagógica ${ }^{(13)}$, pontuam Que esta não se limita a dimensões técnicas, mas faz aflorar o Que há de pessoal em cada sujeito envolvido.

O reconhecimento de Que o professor já não é mais o perito Que sabe tudo, e de que a aprendizagem é um processo constante e dinâmico ao longo da vida, parecem traduzir uma estratégia do professor como formador, aspecto observado nos depoimentos, de Edma "[...] nós discutimos aquela temática [...]", Isaura "[...] diálogo precisa ser trabalhado [...]", Mariana "[...] não sou o poder absoluto [...]", Lais "[...] o aluno tem condições de construir" e Zaira "[...] com a participação do professor, dos alunos e do paciente [...".

Estas professoras, como vemos, constatam a representatividade Que exerce a "parceria professor-aluno" a fim de favorecer o ensino e a aprendizagem, destacando e elucidando a capacidade de negociar, de ouvir as opiniões dos alunos e levá-las em conta. $\mathrm{Na}$ verdade, essa compreensão respalda-se ${ }^{(13)}$ na importância de proporcionar aos alunos situações de aprendizagem diversificadas para Que eles se tornem autônomos nas suas reflexões, nas suas práticas, com direito a ensaios e erros, de modo a tomarem consciência de suas maneiras de aprender, de memorizar e de se comunicar.

Para concluir as considerações analítico-interpretativas dos relatos desta subcategoria, o fazemos recorrendo sobre a metáfora do professor artesão ${ }^{(14)}$, portanto, perfeitamente ajustável ao professor de enfermagem, haja vista Que sua prática pedagógica emerge como momento de construção profissional, no Qual se configura como responsável por adequar conteúdos, escolher estratégias de ensino, a fim de auxiliar a aprendizagem dos seus alunos. Nesta orientação pedagógica de construção/ (re) construção do fazer docente o professor busca despertar outros interesses dos alunos, mobilizando-os para uma participação ativa, por exemplo.

\section{b) Dilemas na organização do trabalho docente}

Prosseguindo com a análise dos dados, na seeüência passamos a trabalhar na dimensão crítico-interpretativa, a subcategoria Que dá visibilidade aos dilemas na organização do trabalho docente. A partir dos depoimentos desta subcategoria, as professoras deixam claro Que enfrentam no cotidiano docente, diversas situações dilemáticas a respeito de como administrar o conteúdo (necessidade de priorizar e selecionar determinados temas) na sala de aula, a fim de proporcionar ao aluno uma aprendizagem significativa e de Qualidade.

Assim, realizamos uma leitura interpretativa do conjunto de dados Que compõem a presente subcategoria, como forma de melhor compreender essa Questão, consignada como relevante em torno da prática pedagógica. Neste sentido, o seguinte bloco de narrativas evidencia o fenômeno em apreço.

Um dos entraves na docência é como conseguir dar um conteúdo por tratar-se de uma disciplina nova. A gente fica receoso e ansioso para saber se o aluno aprendeu (Edma).

Falta aos docentes na universidade uma integração para melhorar a aprendizagem do aluno (Mariana).

Para eu ministrar uma disciplina nova, como a Semiologia, me 
deixa preocupada com o aprendizado do aluno, devido isso eu passo a ir e vir, para com o conteúdo e as demonstrações e de levar ele para o campo de estágio (Lais).

Uma das dificuldades que a gente estar tendo é a necessidade de haver uma integração com as outras disciplinas (Glete).

Nós professores temos que pensar numa forma que a gente tenha de priorizar conteúdos, porQue não adianta você Querer dar tudo, e no fim o que o aluno assimilou daquilo [...], você vai ver, perceber, Que ele não assimilou (Rosi).

Selecionar algumas coisas e aquilo que você considerar importante você colocar, para que o aluno assimile. Você tem Que sentar junto com os alunos e juntos, ver soluções (Edith).

Nos dados constantes nesta subcategoria, as professoras identificam os dilemas em relação ao conteúdo, como constatamos nos seguintes depoimentos: Edma "[...] receoso para saber se o aluno aprendeu [...]", Lais "[...] passo a ir e vir, com o conteúdo [...]", Rosi "[...] priorizar conteúdos [...]" e Edith "[...] sentar junto com os alunos e juntos, ver soluções [...]". Essas dificuldades Que, por vezes, geram dilemas na prática pedagógica, aos poucos estão sendo trabalhadas, pelo conjunto das professoras do Departamento de Enfermagem da UFPI.

Elas apontam a construção do Projeto Político Pedagógico desse curso, como um marco de sustentabilidade das ações socioeducativas da instituição, bem como de respeito a diretrizes curriculares nacionais, configurando-se, desse modo, como um instrumento de trabalho Que sugere o Que vai ser feito, Quando, de Que maneira e por Quem, para com mais segurança chegar aos resultados desejados ${ }^{(15)}$.

Dentre os atuais requerimentos na formação de enfermeiros está a discussão e o direcionamento do projeto político pedagógico dos cursos, não só por determinação legal, mas, sobretudo, pela necessidade de articular a formação às perspectivas do novo mundo globalizado. Um mundo globalizado Que requer mais do Que nunca o pleno exercício da cidadania, da produção do conhecimento, de forma Que a individualidade não seja anulada e o coletivo não seja sinônimo de massificação.

Para fundamentar acerca da compreensão dos dilemas ou dos conflitos presentes no cotidiano da prática pedagógica, valemonos da discussão acerca dos dilemas docentes, segundo Zabalza, Que compreende o conjunto de situações bipolares que se apresentam ao professor no desenvolvimento de sua atividade profissional ${ }^{(16)}$. Estas situações podem ser gerais ou pontuais e o professor tem de fazer opções.

Essa insatisfação colocada pelas professoras pode, de certo modo, ser o catalisador de um processo de busca por novos conhecimentos, indicando Que um processo de reflexão sobre a prática ocorre a partir do conflito entre a realidade encontrada na atuação profissional e os conhecimentos Que detém.

É evidente o entendimento de como a prática docente é fator determinante nas ações do futuro profissional da enfermagem. Pensamos, ou melhor, mais que isto, estamos certos de Que a prática pedagógica certamente influencia de maneira positiva (ou negativa) as ações políticas, éticas e técnicas dessas profissionais.
Para tanto, as professoras interlocutoras apostam numa sistematização dos conteúdos ministrados, assim como numa proposta de avaliação das disciplinas devidamente implementadas. Percebemos nas suas falas, também, Que as professoras Mariana e Glete preocupam-se com a "falta de integração entre as disciplinas e entre os professores e destes com os outros profissionais" com os Quais lidam no cotidiano da prática, principalmente no ambiente hospitalar.

Depreendemos que as professoras do curso de enfermagem vislumbram uma mudança em relação ao pensamento cartesiano, do predomínio das especializações, das práticas institucional médicas onde ainda prevalece o modelo biomédico, no poder da exclusão, exercitando, vivenciando, uma prática Que possibilita uma educação voltada para a liberdade e para a autonomia. Essa realidade põe aspectos de ambigüidade para os discentes no espaço acadêmico de enfermagem eue convivem com outros alunos de outros cursos da área da saúde nos hospitais de ensino e o Que é analisado pelo aluno é um empoderamento dos usuários (clientes).

É importante também fazer uma reflexão mais rigorosa da formação do professor universitário. Diferentemente, de outras modalidades de ensino, esse professor, particularmente no âmbito da enfermagem, se constitui historicamente, tendo como base profissões paralelas que exerce ou exerceu no mundo do trabalho. A idéia de Que "Quem sabe fazer sabe ensinar" deu sustentação à lógica do recrutamento de enfermeiros docentes, durante várias décadas na universidade.

\section{c) Possibilidades de construção de uma prática reflexiva}

Nesta subcategoria os dados evidenciam Que as docentes do curso de enfermagem da UFPI vêm buscando melhorar sua prática docente, notadamente ao revelarem sua disposição de exercitarem uma prática pedagógica Que propicie o diálogo como essência da educação "problematizadora", portanto o antagonista da educação bancária, Que através do caráter reflexivo resulta na inserção crítica à realidade circundante, conforme expresso nas professoras/ parceiras:

Compartilhar os problemas com os colegas professores, com a coordenação, buscando possibilidades de resolução para o desempenho de uma prática comprometida com a sociedade (Mariana).

Eu adoro o ensino através da problematização então faço estudo de caso e dentro desses casos peço para eles dizerem como agiriam. Então o ensino se dá através da técnica da problematização e eles (alunos) adoram, porQue eles dizem Que aprendem muito mais do Que fazer uma coisa tecnicista (Lais).

Quando aprendi Que tinha outras tendências pedagógicas como à da problematização, eu me apaixonei e a partir do momento Que fui atrás do referencial eu melhorei muito minhas aulas, minha presença em sala de aula, busQuei uma participação mais ativa do aluno. [...] eu sempre procurei sair um pouco do retroprojetor, daquela coisa da transmissão (Glete).

Eu consigo mais ou menos mudar essa prática pedagógica tradicional, ou seja, desenvolvendo a metodologia ativa, muito 
mais participativa. Então eu acho interessante você percebe, ver como o aluno cresce como ele se torna reflexivo, participativo, como ele traz para seu contexto, o seu cotidiano e como pode mudar a prática dele depois, a prática social dele (Wanda).

Você precisa fazer uma reflexão do Que ensina numa visão ampla e contínua com os outros professores o Que com certeza vai favorecer o aprendizado (Noraci).

Eu antes fazia uma avaliação da minha matéria, mais era algo muito pequeno, hoje eu vejo através da criticidade, que nós mudamos, $o$ aluno e a escola modificaram-se também e essa análise crítica ocorre por parte de todos na enfermagem (Edith).

Não há mais lugar para o professor que não Questiona o Que faz, também não há lugar para o profissional cheio de técnicas (Zaira).

As professoras interpretam Que a reflexão da prática docente para ocorrer implica em capacidades a serem adQuiridas e aprendidas, não isoladamente, mas num trabalho integrado a outros profissionais. Percebemos, pois, nas narrativas das professoras Mariana: "[...] Compartilhar os problemas [...]" e Noraci: "[...] com os outros professores [...]". Isto favorece um trabalho Que não pode ser desconectado de seu meio, mas a ele estritamente ligado por sucessivas análises, Que conseguem encaminhá-lo à realização de procedimentos Que ultrapassem o ensino, alcançando níveis elevados de elaborações teóricas. Um trabalho isento de neutralidade, mas diretamente envolvido com opções pessoais Que priorizam a crítica, o debate e suas respectivas repercussões.

Observados nos seguintes trechos de falas das professoras, Laís: "[...] se dá através da técnica da problematização [...]" e Glete: "[...] procurei sair um pouco do retroprojetor, daquela coisa da transmissão [...]", através dessas concepções evocadas pelas professoras pode-se compreender o seu universo e as suas ações, o vínculo entre pensamento e a ação do professor inovador, construtor da mudança, traduz-se na utilização de novas práticas pedagógicas.

Na revelação das professoras-parceiras, Wanda, Que se propõe a "[...] mudar essa prática pedagógica mais tradicional [...]"; Edith "[...] vejo através da criticidade [...]", expressa um nível de criticidade Que colocamos como aquele Que seria desejável a todos os professores no desenvolvimento de suas ações de ensino perspectivando assegurar o sucesso de seus alunos; e Zaira, Que reconhecendo ter superado ou dispor de condições de superar o inusitado, o imprevisto, em sala de aula, declara: “[...] não há lugar para o profissional cheio de técnicas [...]". Todas elas dão mostras, como de uma prática reflexiva ${ }^{(17)}$, demonstrada pelo "conhecimento na ação', o Que designa Que o sujeito tem certa consciência de sua própria ação, de sua própria maneira de pensar e de agir profissionalmente.

Assim, demonstram Que são capazes de perceber no interior de sua prática pedagógica a emergência de uma fase de transgressão da concepção de professor como técnico dirigido exclusivamente para a resolução de problemas, por meio da aplicação de regras e de conhecimento numa situação prática. Desse modo, desponta, para nós, a figura do professor reflexivo no campo da enfermagem.
As professoras, em vez de centrarem num modelo de professor como técnico especialista, concebem-no como um profissional Que reflete, toma decisões, e alertam, portanto, para a necessidade de se conceber a formação do professor como um contínuo processo $^{(13,14,18)}$.

A idéia de professor reflexivo, o Qual desenvolve um pensamento reflexivo como objetivo a ser atingido para Que ele seja capaz de forma crítica e sistemática sobre sua prática enQuanto instrumento para desenvolver o pensamento e a ação pedagógica ${ }^{(19)}$. Para o autor, subjacente ao conceito de professor como prático reflexivo, estão considerações sobre a reflexão como um processo Que acontece antes, durante e depois da ação e Que leva o profissional a tomar consciência das metas para as Quais trabalha, a dirigir suas ações por si mesmo. O autor reconhece Que o processo de aprender a ensinar se prolonga durante todo o desenvolvimento profissional, apesar das dificuldades esperadas no mundo real, as Quais extrapolam as salas de aula.

As atitudes necessárias à ação reflexiva podem ser pensadas em termos de atitudes voltadas ao próprio professor de enfermagem, na medida em Que é sincero consigo mesmo e Que se torna responsável, continuamente, por sua aprendizagem e por suas atitudes voltadas ao seu aluno, por meio da análise das conseqüências de seu ensino.

\section{CONSIDERAÇÕES FINAIS}

Todos esses dados incidem sobre o fato de Que as professoras de enfermagem começam a orientar sua conduta e suas decisões a partir de um comportamento crítico-reflexivo sobre si mesmas e sobre suas ações professorais. Tomando por base essa compreensão, é possível afirmar Que o ensino pautado em bases reflexivas se apóia também no pensamento prático do professor, Que, por sua vez, é permeado pelo o enfrentamento de dilemas e suas necessárias superações. Deixam claro Que o desenvolvimento no ensino afigurase fundamental um olhar mais atento sobre a prática pedagógica com suas figurações complexas e instáveis, onde o professor exerce seu protagonismo.

Para tanto, na resolução dos dilemas, geralmente, são acionados aspectos tais como: as crenças do professor, a história dos sujeitos implicados, a percepção da situação, os objetivos, as alternativas de ação disponíveis e as estratégias de resolução. São transformações dessa ordem Que põem em Questão os pressupostos da racionalidade técnica no modelo de formação e de atuação dos professores de enfermagem, provocando as necessárias rupturas nesse processo, expressando um movimento Que conduz à emergência de concepções alternativas sobre o papel do professor, rupturas que levem ao escapamento do modelo do professor como técnico, postulando sua consolidação como prático reflexivo.

Nas evocações narrativas sobre o ensinar no curso de enfermagem, as professoras narraram Que desenvolvem sua prática pedagógica compartilhando saberes com seus alunos e com os pares, discutindo Quando necessário mudanças sobre o ensino e aprendizagem; estimulando os alunos a valorizarem a escola, dialogando e tentando resolver os conflitos presentes colegiadamente.

Na verdade, no contexto geral das categorias objeto de discussão deste artigo evidencia-se como compreensão pontual das 
professoras de enfermagem a disposição de mudar Qualitativamente, pelo investimento em práticas Que visem à superação da reprodução do conhecimento, vislumbrando um trabalho docente diferenciado, desafiador e em bases científicas.

Como encaminhamento conclusivo, reiteramos que as professoras de enfermagem revelam, particularmente, sua disposição de procurar romper com a forma vertical de ensinar ao estimular no aluno o poder da criatividade e da compreensão de realidade em permanente transformação. Ou seja, usarem o conhecimento e a técnica para vencer desafios, e não para padronizar rotinas e condutas de cuidado ao paciente, desafiando seu alunado a participar intensa e criativamente no âmbito de sua prática profissional, evitando separar o pensar do fazer, do saber, do ser professor de profissão.

\section{REFERÊNCIAS}

1. Saviani D. Escola e democracia: teorias da educação, curva da vara, onze teses sobre educação e política. $24^{\mathrm{a}}$ ed. São PauloSP: Cortez; 1991.

2. Perrenoud P. Práticas pedagógicas, profissão docente e formação: perspectivas sociológicas. Lisboa (POR): Dom Quixote; 1993.

3. Sacristán G. Reformas educacionais: utopia, retórica e prática. Brasília (DF): CNTE; 1996.

4. Shigunov Neto A. M, Shizue LB, organizadores. Reflexões sobre a formação de professores. Campinas (SP): Papirus; 2004.

5. Pimenta SG. Professor reflexivo: construindo uma crítica. In: Pimenta SG, Ghedin E, organizadores. Professor reflexivo no Brasil: gênese e crítica de um conceito. São Paulo (SP): Cortez; 2002.

6. Behrens MA. O paradigma emergente e a prática pedagógica. Curitiba (PR): Champagnat; 2003.

7. Alberti V. História oral: a experiência do CPDOC. Rio de Janeiro (RJ): Centro de Pesquisa e Documentação de História Contemporânea do Brasil; 1989.

8. Bardin L. Análise de conteúdo. Lisboa (POR): Edições 70; 1994.

9. Ministério da Saúde (BR). Conselho Nacional de Saúde. Resolução no 196/96. Diretrizes e Normas Regulamentadoras de Pesquisa Envolvendo Seres Humanos. Informe Epidemiol SUS 1996; 5(2): 17-41.

10. Fiorentini D, Souza JR AJ, Melo AGF. Saberes docentes: um desafio para acadêmicos e práticos. In: Geraldi CMG, Fiorentini
D, Pereira EMA, organizadores. Cartografia do trabalho docente: professor (a)-pesquisador (a). $3^{\mathrm{a}}$ ed. Campinas (SP): Mercado de Letras; 2003.

11. Freire P. Pedagogia da autonomia: saberes necessários à prática educativa. São Paulo (SP): Paz e Terra; 1996.

12. Veiga IPA. A prática pedagógica do professor de didática. Campinas (SP): Papirus; 1989.

13. Nóvoa A. Vidas de professores. $2^{\text {a }}$ ed. Porto (POR): Porto Editora; 1992.

14. Nóvoa A. Os professores e a sua formação. Lisboa (POR): Dom Quixote; 1995.

15. Meyer DE, Kruse MH. L. Acerca de diretrizes curriculares e projetos pedagógicos: um início de reflexão. Anais do $6^{\circ}$ Seminário Nacional de Diretrizes para a Educação em Enfermagem. Teresina (PI), Brasil; 2002 maio. Teresina (PI): ABEn-PI; 2002.

16. Zabalza MA. Diários de aula: contributos para o estudo dos dilemas práticos dos professores. Porto (POR): Porto Editora; 1994.

17. Perrenoud P. Dez novas competências para ensinar. Porto Alegre (RS): Artes Médicas Sul; 1999.

18. Schön D. Educando o profissional reflexivo: um novo design para o ensino e a aprendizagem. Porto Alegre (RS): Artmed; 2000.

19. Zeichner KM. A formação reflexiva de professores: idéias e práticas. Lisboa (POR): Educa; 1993. 